\title{
Q-T prolongation secondary to methadone use for severe and resistant restless legs syndrome
}

\author{
Saif Mashaqi \\ Correspondence: saif.mashaqi@sanfordhealth.org

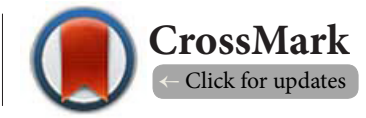 \\ Department of sleep medicine (Sanford Health), University of North Dakota, Grand forks, ND, USA.
}

\begin{abstract}
This case describes a severe restless legs syndrome that was resistant to many therapeutic modalities including first line treatment recommendations. A significant clinical improvement was noticed after the initiation of Methadone $5 \mathrm{mg}$; however, an association with Q-T interval prolongation prompted holding the medication and then reducing the dose to $2.5 \mathrm{mg}$. This side effect of Q-T prolongation has been reported in the literature. Our patient was taking other medications that can potentially cause the same side effect (e.g. Quetiapine). The patient's medical history is significant for nephrotic range proteinuria secondary to membranous glomerulonephritis. The patient does have an underlying moderate obstructive sleep apnea that was treated successfully with CPAP. We highlight through this case the importance of screening patients who get started on Methadone with EKG to get baseline Q-T intervals and monitor the dose accordingly.
\end{abstract}

Keywords: Restless legs syndrome, methadone, Q-T interval, EKG, polysomnography

\section{Introduction}

Methadone is a long acting opioid agonist. It is being used mainly to prevent withdrawal symptoms in opioid abuse. Opioids(Including Methadone) have a good clinical effect in long term use for the treatment of restless legs syndrome and periodic limb movement during sleep that are resistant to first line treatment options [1]. However, side effects can develop with opioids and some of them are serious and life threatening. We report, in this case, a cardiac arrhythmia (Q-T interval prolongation) that was associated with the use of Methadone.

\section{Case presentation}

Our patient is a 41 years old white male who was evaluated at our sleep center for excessive daytime sleepiness and severe restless legs syndrome. He underwent polysomnography which showed a moderate degree of obstructive sleep apnea (AHI 17 events/hour). He was treated with CPAP $17 \mathrm{cmH} 2 \mathrm{O}$ which helped partially with hypersomnia. He continued to complain of severe restless legs symptoms. Multiple therapies were used, including Ropinirole $0.25 \mathrm{mg}$, the dose was gradually increased over four weeks up to $1 \mathrm{mg}$ with no relief, Pramipexole 0.125 $\mathrm{mg}$ up to $0.5 \mathrm{mg}$ over four weeks with no response, Gabapentin $300 \mathrm{mg}$ up to $900 \mathrm{mg}$ with no success and Pregabalin $150 \mathrm{mg}$ which helped partially but caused significant drowsiness in the morning and subsequently it was discontinued. The use of opioids (mainly Methadone) was discussed with the patient and a dose of $5 \mathrm{mg}$ was started with significant improvement in RLS symptoms within a week. The patient reported better sleep quality and he denied daytime sleepiness. However, an EKG was obtained two weeks after starting Methadone that showed prolongation of Q-T interval (Q-Tc 482 milliseconds). Q-T interval before starting Methadone was 459 milliseconds. As a result, Methadone was held for two weeks and a repeat EKG showed a Q-T interval back to baseline at 453 milliseconds. Methadone was restarted at a lower dose of $2.5 \mathrm{mg}$ and a repeat EKG showed Q-T interval "Q-Tc" of 460 milliseconds.

The patient does have a medical history significant for nephrotic range proteinuria secondary to membranous glomerulonephritis. Estimated Glomerular filtration rate (GFR is $27 \mathrm{ml} / \mathrm{min}$ ) and creatinine clearance is $39 \mathrm{ml} / \mathrm{min}$ and that did not require renal adjustment for Methadone dose.Liver function test was within normal limits.

\section{Discussion}

Restless Legs Syndrome can sometimes be very severe and resistant to many treatment modalities. Dopaminergic agonists (Including Ropinirole and Pramipexole) are the first standard treatment [1]. Opioids can be used but their level of evidence 


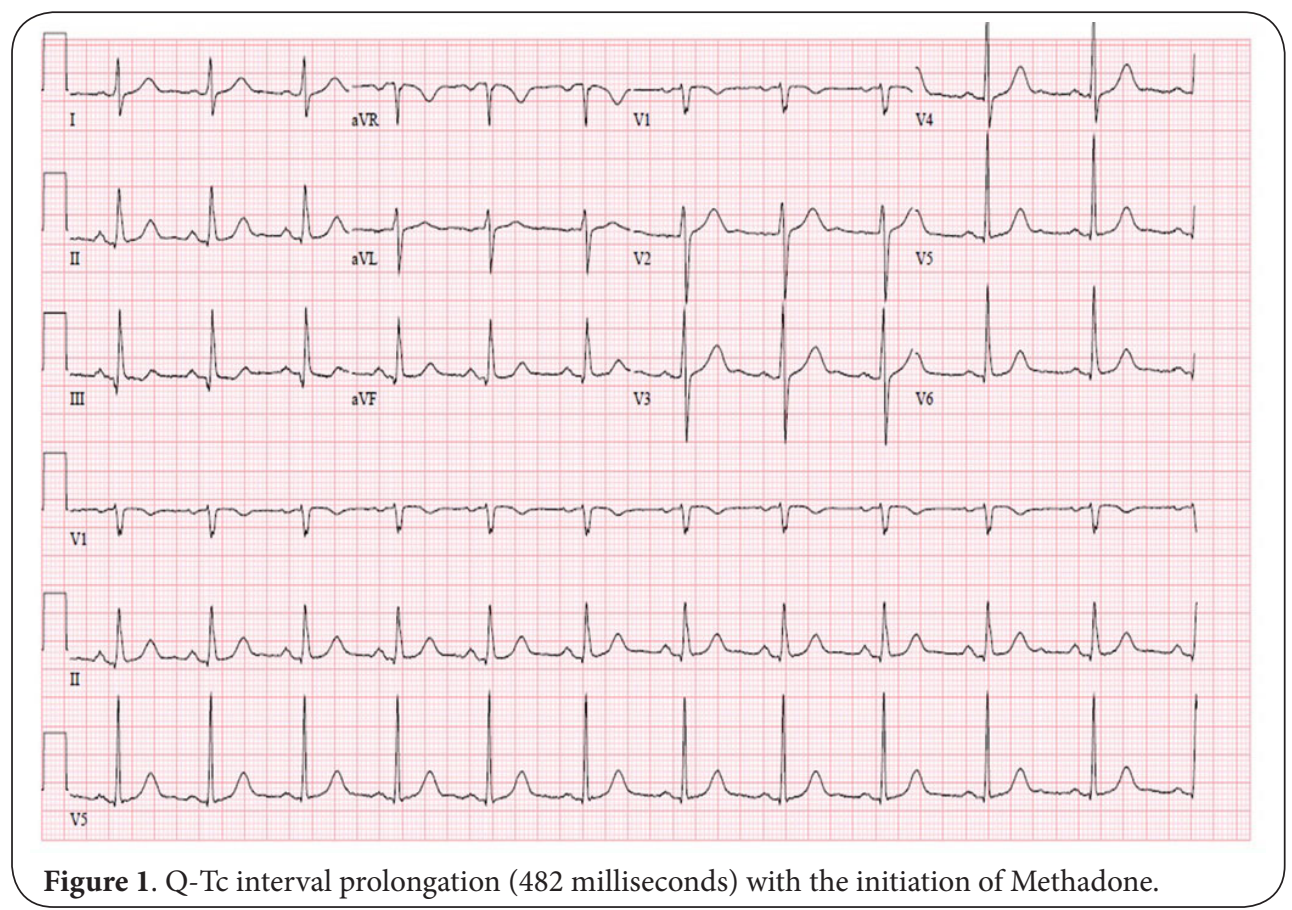

is low [1]. They have a good clinical outcome especially in the long term in severe cases. One of the potential dangerous side effects is cardiac arrhythmia (mainly Q-T prolongation). This is mainly noticed with Methadone [2]. The exact pathophysiology is not clear. Methadone metabolites [3], interaction with other medications that cause Q-T prolongation (e.g., antibiotics and atypical antipsychotics) $[4,5]$, hepatic dysfunction and electrolytes abnormalities [6] are potential mechanisms. Although our patient's medications include Quetiapine which is an atypical antipsychotic that is known to cause Q-T prolongation, he was on this medication for many years and his baseline Q-T was 459 milliseconds. The sudden increase to 482 milliseconds was noticed two weeks after the initiation of Methadone and resolved with holding the medication (Figure 1). Liver function test and basic metabolic panel was within normal limits.

This case highlights the importance of screening patients with EKG to get a baseline Q-T interval before the initiation of Methadone to treat resistant RLS. To our knowledge, this will be the first case of Q-T prolongation secondary to Methadone use is severe and resistant RLS reported in sleep medicine literature.

\section{List of abbreviations}

RLS: Restless Legs Syndrome

EKG: Electrocardiogram

CPAP: Continuous Positive Airway Pressure

AHI: Apnea Hypopnea Index

EGFR: Estimated Glomerular Filtration Rate

ALT: Alanine aminotransferase

AST: Aspartate aminotransferase

BUN: Blood Urea Nitrogen

\section{Competing interests}

The author declares that he has no competing interests.

\section{Acknowledgement}

Work for this case report was performed at Sanford Sleep center/ University of North Dakota. 2801 University Dr. South, Fargo, ND.

\section{Publication history}

Senior Editor: Thomas Müller, Alexianer St. Joseph-Krankenhaus Berlin-Weissensee, Germany.

Received: 09-Dec-2016 Final Revised: 23-Feb-2017

Accepted: 28-Feb-2017 Published: 08-Mar-2017

\section{References}

1. Aroura RN. Practice Parameters with an Evidence Based Systematic Review and Meta-Analysis. JCSM. 2012; 35:1039-62.

2. Kao DP, Haigney MC, Mehler PS and Krantz MJ. Arrhythmia associated with buprenorphine and methadone reported to the Food and Drug Administration. Addiction. 2015; 110:1468-75. | Article | PubMed Abstract | PubMed FullText

3. Carlquist JF, Moody DE, Knight S, Johnson EG, Fang WB, Huntinghouse JA, Rollo JS, Webster LR and Anderson JL. A Possible Mechanistic Link Between the CYP2C19 Genotype, the Methadone Metabolite Ethylidene-1,5-Dimethyl-3,3-Diphenylpyrrolidene (EDDP), and Methadone-Induced Corrected QT Interval Prolongation in a Pilot Study. Mol Diagn Ther. 2015; 19:131-8. | Article | PubMed

4. Winton JC and Twilla JD. Sudden cardiac arrest in a patient on chronic methadone after the addition of azithromycin. Am J Med Sci. 2013; 345:160-2. | Article | PubMed

5. Kim A, Lim KS, Lee H, Chung H, Yoon SH, Yu KS, Cho JY, Jang IJ and Chung JY. A thorough QT study to evaluate the QTc prolongation potential of two neuropsychiatric drugs, quetiapine and escitalopram, in healthy volunteers. Int Clin Psychopharmacol. 2016; 31:210-7. | Article | PubMed

6. Cruciani RA, Sekine R, Homel P, Lussier D, Yap Y, Suzuki Y, Schweitzer P, Yancovitz SR, Lapin JA, Shaiova L, Sheu RG and Portenoy RK. 
Saif Mashaqi, Neuroscience Discovery 2017,

http://www.hoajonline.com/journals/pdf/2052-6946-5-1.pdf

Measurement of QTc in patients receiving chronic methadone therapy. J

Pain Symptom Manage. 2005; 29:385-91. | Article | PubMed

\section{Citation:}

Mashaqi S. Q-T prolongation secondary to methadone use for severe and resistant restless legs syndrome.

Neurosci Discov. 2017; 5:1.

http://dx.doi.org/10.7243/2052-6946-5-1 